\title{
WAT LEER CALVYN EN LUTHER OOR DIE MAAGDELIKE GEBOORTE VAN JESUS CHRISTUS
}

DR. P. J. T. KOEKEMOER

\section{JOHANNES CALVYN.}

Wanneer mens die Christologie van Calvyn in oënskou neem, sê Egbert EMMEN in sy dissertasie, is daar drie gesigspunte opvallend: ${ }^{1}$ )

(A) 'n Teologiese: dit wil sê die leer oor die Persoon van Christus in sy betrekking tot God die Vader. Hier is Calvyn se leer oor die Triniteit, Inkarnasie en Versoening ter sprake:

(1) Christus is die Seun van God. Sy plek in die Heilige Drieeenheid volgens Calvyn word duidelik in sy kontrovers met Caroli, Servet en Gentiles.

(2) Christus is die Openbaring van God. Hier ter sprake is: -

(a) Christus en die Skepping.

(b) Die Inkarnasie, vgl. die polemiek met Sadoletus, Servet en Osiander.

(c) Die versoening: Hier ter sprake is

(i) die ampte van Christus,

(ii) die offer van God,

(iii) die Anselmiaanse Versoeningsleer,

(iv) die praedestinasie in sy samehang met die Christologie.

(B) 'n Antropologiese: Wat is die verhouding van Christus tot die skepsel, die mens, vgl. hier:

(1) Christus as mens: Een Persoon met twee nature.

(2) Christus en die mens. Regverdiging (teen Osiander) en Heiliging, die "nuwe mens" en boetedoening.

(3) Die navolging van Christus, Christus as .Voorbeeld".

(C) 'n Ekklesiologiese: Wat is die verhouding van Christus tot sy kerk, in Woord en sakramente.

(1) Die maagdelike geboorte:

Calvyn bring die maagdelike geboorte van Christus ter sprake onder die antropologiese gesigspunt van sy Christologie. Calvyn bely sy mensheid met nadruk, maar altyd so dat die heilsinteresse op die voorgrond tree. ${ }^{2}$ ) Die geboorte

\footnotetext{
1) Egbert Emmen: De Christologie van Calvyn. Dissertasie, Groningen, 1935, bls. 7 v.v.

2) Vgl. Institusie II, 13, 1 .
} 
van Christus uit die maagd Maria geskied ter versoening van die mens. Wanneer Calvyn in sy Institusie handel oor die "vere homo", die aanname van die ware van die menslike vlees, teenoor die docetiese dwalinge, dan wys hy daarop dat die seën nie beloof word in die vorm van ' $n$ hemelse saad (teenoor die leer van Mani) of die skyngestalte van ' $n$ mens nie, maar in die saad van Abraham en Jakob, (Gen. 22:18, 26:4) dat die ewige troon beloof word aan die Seun van Dawid en die vrug van sy lende. (Ps. 45:7.) Daarom word $\mathrm{Hy}$, toe $\mathrm{Hy}$ in die vlees geopenbaar was, genoem die Seun van Dawid en Abraham (Mat. 1:1), nie alleen daarom, omdat $\mathrm{Hy}$ uit die skoot van 'n maagd gebore is nie... maar omdat $\mathrm{Hy}$, volgens die uitleg van Paulus (Rom. 1:3) na die vlees gebore is uit die geslag van Dawid, soos dieselfde apostel elders (Rom. 9:5) leer, dat $\mathrm{Hy}$ uit die Jode stam. ${ }^{3}$ ) Ook die uitdrukking, .,Seun van die mens", sien Calvyn in die betekenis van die Hebreeuse spreekwyse, dat daarmee bedoel word 'n ware mens. „Deur hierdie manier van spreke word die ware menslike natuur van Christus uitgedruk, want alhoewel Hy nie onmiddellik uit ' $n$ sterflike vader gebore is nie, het sy oorsprong uit Adam voortgekom. ${ }^{4}$ )

Alhoewel die geslagsregister van Mattheus nie die voorouers van Maria aantoon nie, maar die van Josef, ag Mattheus dit tog voldoende omdat hy praat oor 'n saak wat toentertyd algemeen bekend was, dat Josef uit die geslag van Dawid was en dat voldoende vasgestaan het dat Maria uit dieselfde huis was. Nog meer nadruk lê Lukas daarop deur te leer dat die saligheid wat deur Christus gebring is, vir die hele menslike geslag geld, omdat Christus, wat die heil bewerk, uit Adam, die gemeenskaplike vader van almal, stam. "Ek erken wel", sê Calvyn, „, dat uit die geslagsregister niks anders uitgemaak kan word nie as dat Christus die Seun van Dawid is in soverre Hy gebore is uit ' $n$ maagd.") Calvyn noem die Marcioniete ' $n$ bende wat geen skaamte meer het nie omdat sommige van hulle die onbeskaamde vraag aan die gelowiges stel, of Christus dan voortgekom het uit die „semen" van die maandstonde van die maagd. „Maar ek vra op my beurt of Hy nie gegroei het in die bloed van sy moeder nie? ... Heeltemal juis word dus uit die woorde van Mattheus afgelei, dat Christus, omdat Hy uit Maria gebore is en voortgekom het uit haar saad, net soos

3) Institusie II, 13, 2.

4) Institusie 11, 13, 3 .

s) Institusie II, 13, 3 . 
wanneer gesê word dat Boas gebore is uit Ragab, (Mat. $1: 5)$ ' $n$ gelyke voortbrenging aangedui word. ${ }^{6}$ ) "Mattheus beskryf die maagd nie as ' $n$ buis waardeur Christus gevloei het nie" sê Calvyn, .,maar hy onderskei hierdie wonderbare wyse van voortbrenging van die gewone manier, $\mathrm{nl}$. dat Christus deur haar uit die saad van Dawid voortgebring is. Want op dieselfde wyse waarop gesê word dat Isak uit Abraham, Salomo uit Dawid, Josef uit Jakob gebore is, word gesê, dat Christus uit sy moeder gebore is. Want die evangelis het sy woorde so aaneengeskakel, en wanneer hy wil bewys, dat Christus sy oorsprong het in Dawid, is hy tevrede met hierdie een feit, dat $\mathrm{Hy}$ uit Maria gebore is. Daaruit volg, dat hy as ' $n$ bekende saak aangeneem het dat Maria 'n bloedverwant was van Josef. i)

Calvyn wys in sy Kommentaar daarop dat Mat. 1:16 en Luk. 3:23 nooit die bedoeling het om Josef as die verwekkende vader daar te stel nie, want voordat hy die genealogie afsluit, wys Mattheus daarop dat Christus ontvang is in die skoot van die maagd Maria, nie uit die saad van Josef nie, maar deur die werking van die krag van die Heilige Gees. Ook Luk. 3:23 sê dat hulle gemeen het dat Hy die Seun van Josef was. ${ }^{8}$ ) Mat. 1:18 dui nie die wyse van geboorte van Christus aan nie maar die wyse waarop sy hemelse herkoms aan Josef bekendgemaak is, $\mathrm{nl}$. dat Maria swanger bevind is deur die Heilige Gees, gedurende die tyd van hulle verlowing. (Volgens Joodse wet is hulle dan reeds "man en vrou", die huweliksgemeenskap uitgesluit. „Voordat hulle saamgekom het", kan dui op die huweliksgemeenskap, maar kan ook gewoonweg beteken: .,voordat hulle saam gaan woon het as man en vrou, as een familie". ${ }^{9}$ )

Toe die Seun van God na ons gekom het in die vlees, het $H y$ van die Vader 'n naam ontvang wat duidelik sê met watter doel $\mathrm{Hy}$ gekom het, wat sy mag is en wat ons van Hom kon verwag. Die naam Jesus kom van die Hebreeuse werkwoord in die Hiph. vorm, hošica, wat beteken om te red of te verlos. Die woorde van die engel: „Hy sal sy volk van hulle sonde verlos" veronderstel in die eerste plek dat diegene na wie toe Hy gestuur is, in sigself verlore is, dat hulle buite die ewige lewe staan vanweë hulle

\footnotetext{
c) Irstitusie II, 13, 3.

i) Institusie II, 13, 3.

8) John Calvin: Commentary on a Harmony of the Evangelists, Matthew, Mark and Luke; Translated from the Original latin by the Rev. William Pringle.

9) Calvin: Commentary, Deel i, bls. 93, 94.
} 
sonde. Die verlossing bestaan uit twee dele, t.w. boetedoening en versoening met God. ${ }^{10}$ )

Die geboorte van die Messias, aangekondig in Jes. 7:14, dui daarop dat die profeet spreek van 'n wonderbaarlike en buitengewone geboorte. Die Here self sal die teken gee, 'n buitengewone teken. Die calmâ sal swanger word... terwyl die aandeel van die man nie eens genoem word nie. So wil die profeet die aandag trek op die ongewone van die teken: 'n maagd sal ontvang sonder die toedoen van die man. ${ }^{11}$ ) Die moeder sal die naam aan die Kind gee, nie kragtens die outoriteit en toestemming van die man nie - die man word in alle opsigte uitgesluit. ${ }^{12}$ )

Of Maria ná die geboorte van Jesus nog maagd gebly het, kan uit Mat. 1:25, nie besluit word nie .Dat $\mathrm{H}_{y}$ die eersgeborene genoem word, kan alleen beteken dat Hy uit 'n maagd gebore is, iemand wat nog nie voorheen 'n kind gehad het nie. Wat ná die geboorte plaasgevind het, word ons nie berig nie. lemand wat hieroor vrae stel, doen dit uit nuuskierigheid en mense wat hieroor wil argumenteer, doen dit uit hulle liefde vir disputering. ${ }^{13}$ )

Calvyn gaan in verband met die maagdelike geboorte ook in op die bewerings van die Marcioniete, as sou die geboorte van Christus uit 'n mens, Hom in verband bring met die erfsonde. Hierteenoor eksegetiseer Calvyn Rom. 5:12, I Kor. 15:47 en Rom. 8:3. Dat Christus gekom het „,in die gelykheid van sondige vlees", om aan die wet te voldoen, sonder Hom uitdruklik af van die gemeenskaplike lot (van die erfsonde) sodat Hy kan wees 'n waaragtige mens sonder fout en gebrek. ,.Kinderagtig redeneer hulle dat indien Christus vry is van alle smet en deur die verborge werking van die Gees gebore is uit die maagd Maria, dat dan klaarblyklik die saad van die vrou nie onrein is nie, maar slegs die van die man". ${ }^{14}$ ) ,Maar ons maak Christus nie vry van alle smet, omdat Hy slegs uit ' $n$ moeder gebore is sonder die toedoen van 'n man nie, maar omdat $\mathrm{Hy}$ geheilig is deur die Gees, omdat sy geboorte suiwer en rein sou wees, net soos dit sou wees voor die val van Adam" sê Calvyn. ${ }^{15}$ )

Volgens die Institusie van Calvyn kom mens tot die gevolgtrekking dat die maagdelike geboorte 'n wesenlike element in die Inkarnasie is: „Wat gesê word, (Joh. 1:14), dat die

10) Calvin: Commentary, Deel 1, bls. 98, 99.

11 Calvin: Commentary, Deel 1, bls. 104.

12 Calvin: Commentary, Deel 1, bls. 104.

13) Calvin: Commentary, Deel 1, bls. 107.

14) Institusie II, 13, 4.

15) Institusie II, 13, 4. 
Woord vlees geword het, moet nie so verstaan word nie, as sou dit óf in vlees verander word, of met vlees geheel en al vermengd is; maar dit word gesê: omdat die Woord uit die skoot van die maagd vir Hom in tempel gekies het, om daar in te woon, en Hy, wat die Seun van God was, die Seun van die mens geword het, nie deur vermenging van wese nie, maar deur eenheid van die Persoon. Ons sê immers dat die Godheid so met die mensheid verbonde en verenig is, dat elkeen van beide nature sy "eienaardigheid" geheel behou, en tog uit die twee, een Christus tot stand gebring het."1")

\section{DIE ROOMS-KATOLIEKE MARIA-VERERING.}

Calvyn tree skerper en kragtiger as Luther op teen die R.K. Maria-verering. By hom vind ons geen langsame breuk met die Rooms-Katolieke Kerk nie. Die verering van Maria en die heiliges verwerp hy op grond van die Middelaarskap van Christus. Christus mag nie op die tweede plek gebring word nie. ${ }^{15}$ ) Met krasse taal veroordeel hy die verering van die heiliges as duiwelse onbeskaamdheid, stompsinnigheid en raserny. Sy vernaamste besware kan in vyf punte saamgevat word. ${ }^{18}$ )

(1) God word van sy eer beroof.

(2) God word nie vertrou nie.

(3) Die geloof (fides fiducialis) word vernietig.

(4) Christus is nie meer die enige Middelaar nie.

(5) Dit is ' $n$ onbybelse wyse van aanbidding.

In sy geskrif teen die Paryse Teologiese Fakulteit sê hy aangaande die heiliges: cultum vero illis exhibere . . p profana est superstitio. ${ }^{19}$ ) Ten sterkste is hy gekant teen die aanroeping van die heiliges gedurende die mis: „Ut . . . Sancti pro diis invocarentur.“20) Die verering van beelde en relikwieë is afgodery. ${ }^{21}$ ) In sy traktaat „De Reliquiis" verwerp hy alle relikwieë van Maria en sê hy: „Daar het allerlei soorte van gebede voorgekom met verskriklike godslasteringe, soos bv. hierdie woorde tot die maagd: Jube natum, jure matris impera, portus salutis, vita, spes nostra." ${ }^{22}$ )

16) Institusie II, 14. 1.

17) Calvyn: Opera Omnia. Amstlod. 1671. VI, 13a. Hinc factum est ut Christo velut in subsellium redacto, prima sedes Mariæ tribueretur.

18) Institusie III, H.2O.

10) Opera VIII, $195 \mathrm{v}$.

20) Opera VIII, 292 en 438.

21) Opera VIII, 110 b.

22) Opera VIII, 94a. en 203b. vgl. ook Opera VI, 26 en VI, 14a (Papistae) magnificos imo plusquam superbos titulos affatim congerunt: quod sit regina coeli, stella salutis, porta vitae, dulcedo spes et salus. Quin etiameo imbudentiae et furoris ipsos proripuit Satan, ut imperium illi in Christum traderent: Haec enim est oerum catilena: Roga Patrem jube natum. 
Calvyn ontken die sondeloosheid van Maria ${ }^{23}$ ) en noem haar sg. durende maagdelikheid ' $n$ absurditeit: perfide enim passa fuisset se marito collocari sanctumque conjugii foedus non sine Dei ludibrio sprevisset. ${ }^{24}$ ) Of sy ná die geboorte van Christus met Josef geslagtelike omgang gehad het, is onbekend; mens vind dit nie in die Skrif nie. ${ }^{25}$ ) Christus was self geen voorstander van die Maria-verering in die sin van die Rooms-Katolieke Kerk nie. In sy kommentaar op Luk. 2:27 sê Calvyn dat Christus in sy antwoord die vrou berispe het omdat sy nie alle lof aan Christus gebring het nie, terwyl hy in Mat. 12:48 en 49 'n vermaning aan die adres van Maria vind. ${ }^{26}$ )

Toe die Teologiese Fakulteit van Parys in 1543 'n geloofsbelydenis opgestel het as 'n teenvoeter teen die reformasie, het Calvyn daarop geantwoord. ${ }^{2 i}$ ) In verband met artikel 12 (,Dit is 'n heilige en Gode welbehaaglike saak dat mens tot die welgeluksalige maagd Maria en die ander heiliges wat in die hemel is, sal bid omdat hulle pleitbesorgers vir ons sal word") antwoord Calvyn dat die Skrif eis dat ons in die geloof sal bid (Mrk. 11). Die geloof kom voort uit die Woord van God (Rom. 10). As ons aan die Woord van God gehoorsaam wil wees, moet ons een enige God aanroep in die naam van Jesus Christus (Ps. 50 en 91, Joël 2). Dit is die geestelike diens van sy Naam (Jer. 29 en I Tim. 2.). Hy het ons sy Seun gegee as die enige Middelaar (Joh. 10, 14, 16) deur wie se voorbede ons in vertroue toegang tot God het (Efes. $3 \mathrm{vgl}$. ook Hebr. 4). Daar is voorts geen enkele bevel om toevlug te soek by die voorbedes van die heiliges nie.

Daarom is hierdie wyse van aanbidding in stryd met die Heilige Skrif. Nóg die profete, nóg die apostels het ons so 'n voorbeeld gegee. Wat betref die feit dat die Heilige Gees ons beveel om vir mekaar te bid, dit het betrekking op hierdie lewe. Spottend vra Calvyn of die heiliges wel sulke groot ore het dat ons gebede tot hulle kan deurdring. ${ }^{28}$ )

Wat betref die neerkniel voor die kruisbeeld of die beelde van die maagd Maria en ander heiliges (Art. 16), verwys Calvyn na die dekaloog (Ex. 20 en Deut. 5). Om te aanbid beteken om neer te kniel. Al sou diegene wat "skerper van gees" is, ontken dat hulle die beeld aanbid en sê dat hulle in die sigbare gestalte die teken sien van die saak waarom dit gaan ... dan moet ons daaraan dink dat die swakkes verlei word om heidens daaroor te dink $\mathrm{nl}$. dat daar 'n krag in die beeld self skuil. ${ }^{29}$ )

\footnotetext{
23) Opera VIII, 252a.

24) Opera VI, 11 a.

25) Opera VI, 26.

20) Opera VI, 142

2: Johannes Calvyn: De Artikelen van de Faculteit der Heilige Godgeleerdheid te Parijs met de remedie tegen het Venijn.

29) Johannes Calvijn, De Artikefen..., A.W. bls. 54.

29) Johannes Calvijn, De Artikelen.... A.W. bls. 62 en 63.
} 


\section{CALVYN SE WAARDERING VAN DIE MAAGDELIKHEID EN DIE STAAT VAN DIE HUWELIK.}

Wanneer Calvyn wel waardering van die maagdelikheid daarop nahou, grond hy dit nie op die Maria-leer nie, maar wel op die Heilige Skrif (sola Scriptura). In sy uitleg van die sewende gebod sê hy: ${ }^{30}$ ) „Die maagdelike kuisheid is, erken ek, 'n deug wat nie te min geag moet word nie." Hy wil sy waardering van die maagdelikheid as deug in verband bring met die skriftuurlike verstaan daarvan as ' $n$ genade-gawe wat beslis nie aan elkeen gegee is nie. (Mat. 19:12 en I Kor. 7:7.) „Aangesien dit sommige ontsê is en andere slegs vir ' $n$ tyd toegestaan is, moet diegene wat deur gebrek aan selfbeheersing gekwel word en in die stryd nie die oorhand kan behou nie, hulle begewe tot die steun wat die huwelik bied, om so na die graad van hulle roeping, die kuisheid te dien ... die Here verseker (Mat. 19:12) dat die onthouding ' $n$ besondere gawe van God is en behoort tot die soort van gawes, wat nie sonder onderskeid en ook nie in die algemeen aan die liggaam van die kerk geskenk word nie, maar aan weinige lede."

Calvyn sê (teen die Rooms-Katolieke beskouing bedoel) ons verset ons teen God wanneer ons ons lewenswyse nie laat aansluit by die maat van ons vermoë nie. "Die Here verbied ons die ontug; dus eis $\mathrm{Hy}$ van ons reinheid en kuisheid. Daar is een middel om dit te bewaar, naamlik dat elkeen sigself sal afmeet met sy eie maat. Niemand mag die huwelik ligvaardig verag as 'n saak wat vir hom onnuttig of oortollig is nie; niemand mag die ongehude staat anders begeer as dan wanneer hy ' $n$ huisvrou kan ontbeer nie ... en aangesien aan baie hierdie weldaad (van onthouding) slegs vir ' $n$ tyd geskenk word, moet elkeen hom solank van die huwelik on thou, as wat hy geskik is om die ongehude staat te bewaar" (1 Kor. 7:2, 9). ${ }^{31}$ )

"Aangesien die mens geskape is onder hierdie wet, dat hy nie 'n eensame lewe sou lei nie, maar ' $n$ aan hom toegevoegde hulp sou gebruik en hy vervolgens ten gevolge van die vloek van die sonde nog meer aan hierdie noodsaaklikheid onderworpe is, het die Here ons, vir sover dit genoeg was, in hierdie opsig gehelp dat $\mathrm{Hy}$ die huwelik ingestel het, waarvan $\mathrm{Hy}$ die gemeenskap, wat deur sy gesag aangegaan is, ook deur sy seën geheilig het.." ${ }^{\prime 32}$ )

Sy kritiek op die Rooms-Katolieke selibaat kom vanuit die Heilige Skrif. „Die gelofte van die selibaat keur ons om geen ander rede af nie dan wel omdat dit verkeerdelik vir 'n deel van die godsdiens gehou word en ligvaardig gedoen word deur hulle wat die gawe van die onthouding nie ontvang het nie. ${ }^{{ }^{\prime \prime 3}}$ )

30) Institusie II, 8, 42.

31) Institusie II, 8, 43.

32) Institusie II, 8, 41.

33) Institusie IV, 13, 18. 
Die nonne kan hulle ook nie op Paulus beroep nie. „Want die diakonesse is gekies, nie om deur gesang of onverstaanbare gemompel God te streel en die res van die tyd in ledigheid te lewe nie, maar om die openbare diens van die kerk teenoor die armes waar te neem en sig met alle ywer, naarstigheid en vlyt toe te lê op die pligte van die liefde. Hulle het nie die gelofte om ongehuud te bly, gedoen om God enige erediens te bewys deur hulle te onthou van die huwelik nie, maar slegs omdat hulle vaardiger sou wees in die uitvoering van hulle amp. “"34)

Die verbod op die priester-huwelik noem Calvyn 'n „goddelose tirannie, nie alleen teen Gods Woord nie, maar ook teen alle billikheid". ${ }^{35}$ ) Die mens kan nie verbied wat God vrygelaat het nie. Calvyn beroep hom telkens op die Heilige Skrif en in hierdie verband op I Tim. 3:2, Titus 1:6. Diegene wat die huwelik verbied, is bedrieërs en duiwels ( 1 Tim. 4:3). „Paulus reken onder die deugde van die biskop die huwelik. Maar hulle leer dat dit 'n geestelike en ondraaglike fout is ... Christus ag die huwelik hierdie eer waardig dat dit sy wil is dat dit ' $n$ beeld van sy heilige verbintenis met die kerk is. Sou daar iets skoners gesê kan word om die waardigheid van die huwelik aan te prys? Met welk 'n onbeskaamdheid sal dit dan onrein of besmet genoem word, terwyl die gelykenis van die geestelike genade van Christus daarin skitter?"36)

„Hulle hoor die Woord van God aangaande die algemene toestand van die mense: Dit is nie goed dat die mens alleen is nie (Gen. 2:18) ... Laat hulle in so 'n hardnekkigheid God nie as helper verwag nie, maar laat hulle veelęer dink aan wat gesê is: Jy mag die Here, jou God, nie versoek nie. Want dit is God versoek: om in te gaan teen die deur Hom ingeplante natuur... hulle durf ook die huwelik, welke instelling God nie strydig geag het met sy majesteit, wat $\mathrm{Hy}$ onder almal eerbaar verklaar het (Hebr. 13:4), wat Christus onse Heer, deur sy teenwoordigheid geheilig het (Joh. 2:2 v.v.), wat Hy waardig gekeur het en met sy eerste wonder geëer het, 'n bevlekking noem: alleen om hulle selibaat, hoe dit ook sy, met wonderlike lofprysinge te verhef, asof hulle nie self in hulle lewe 'n duidelike bewys lewer dat die selibaat iets anders is as maagdelikheid ....3i)

\section{KONKLUSIES.}

(1) CALVYN handhaaf die Skrifbewys, en daarmee die maatstaf van die Openbaring. Voorafgaande paginas bewys dat die maatstaf van "die Skrif alleen", nie alleen in teorie nie, maar in sy daaglikse gesprek 'n eersterangse plek inneem, bv. die talle Skrifsitate en eksegese.

34) Institusie IV, 13, 19.

35) Institusie IV, 13, 23.

36) Institusie IV, 12, 24.

3i) Institusie IV, 12, 3. 
( 2) Waaroor CALVYN ookal mag handel - orals vind ons christologiese interesse. EMMEN het aangetoon hoe sy leer oor die Triniteit, Inkarnasie en Versoening, sy Skeppingsleer, Antropologie en Ekklesiologie christologies bepaald is.

( 3) Baie duidelik tree die heilsinteresse op die voorgrond wanneer CALVYN oor die maagdelike geboorte van Christus handel: dit het versoening moontlik gemaak. Daarmee staan ons in die hart van die reformatoriese dogmatiek.

(4) Hy bring die maagdelike geboorte in verband met die mensheid, die "vere homo" van Jesus Christus. Dit onderstreep sy egte mensheid bv. sy verklaring van "Seun van die mens".

(5) CALVYN is voortdurend besig om vanuit die Nuwe Testament (vgl. Johannesbriewe) en die regsinnige patres, dwaalleringe te weerlê. Die geboorte van Jesus uit die maagd Maria gebruik hy as 'n argument teen die docetisme.

(6) Teenoor die Joodse ongeloof en Joodse lastergerugte verbind hy Jesus Christus met Dawid, om daarmee sy Dawidseunskap en sy Messiasskap suiwer te stel, in ooreenstemming met wat Paulus leer in Rom. 1:3, 9:5.

( 7) Die maagdelikheid as 'n etiese deug het volgens CALVYN niks te doen met die sondeloosheid van Christus nie. Christus is nie vry van sondesmet omdat Hy uit ' $n$ maagd en sonder die toedoen van ' $n$ man gebore is nie, maar omdat $\mathrm{Hy}$ geheilig is deur die Gees van God, dus deur die spreke van God self. Calvyn knoop geen etiese ideale vas aan die maagdelikheid van Maria nie.

( 8) Die „qui conceptus est de Spirtu Sancto, natus ex Maria virgine" beteken dat die goddelike natuur so met die menslike natuur verbonde is dat elkeen van beide nature sy „eienaardigheid" geheel behou, maar altyd so (contra Nestorius) dat ons slegs van een Christus moet praat.

(9) Die verering van die heiliges en Maria in die Rooms-Katolieke sin, verwerp hy op grond van die enige middelaarskap van Christus, op grond van die Heilige Skrif, as bygeloof en onsin.

(10) Calvyn se waardering van die maagdelikheid as deug, grond hy nie op die Maria-leer nie maar op die sola Scriptura, insoverre die maagdelikheid as genadegawe voorgehou word, na die graad van die roeping van elke mens, na die maat van ons vermoë. Die selibaat as verpligting op hulle (die priesters en nonne) wat die gawe van die onthouding nie ontvang het nie, is teen die Woord van God en 'n goddelose tirannie in die Rooms-Katolieke Kerk. Dit het tot gevolg 'n verkleinering van die ander deur God gewilde, deur Christus Self geheiligde lewensstaat, die huwelik. Hierdie minagting vir die huwelik is ook allermins te regverdig uit die Heilige Skrif; inteendeel: Calvyn fundeer die huwelik suiwer skriftuurlik. 


\section{LUTHER.}

Luther se beskouinge oor die maagdelike geboorte van Jesus soos dit teruggevind word in sy "Cathechismus minor" en "Cathechismus major", en sy invloed op die "Confessio Augustana" en die latere "Formula Concordiae", sal in oënskou geneem moet word. Ons volstaan egter in hierdie verband met die opmerking dat uit bogenoemde Lutherse Konfessies blyk dat Luther die parthenogenesis op een lyn, saam met al die ander christologiese artikels van die apostolicum plaas, dat hy ook hierdie artikel beskou as „articulus de redemptione", as wenslike stuk in die leer van die Verlossing, d.w.s. as ' $n$ heilsfeit. ${ }^{38}$ )

Dit is duidelik dat Luther se beskouings oor die Rooms-Katolieke Mariologie veranderinge ondergaan het, dat hy hom deur die loop van jare grootliks ontworstel het aan die ou "Roomse suurdeeg". Die Rooms-Katolieke teoloog KEMNA, ${ }^{39}$ ) stel dit dan ook so dat die „enkele lofreëls oor Maria" by Luther, niks anders is as "RoomsKatolieke reste by die gevoelsmens" nie. ${ }^{40}$ )

KEMNA is reg wanneer hy beweer „dat er bij de eerste hervormers en in het Protestantisme geen sprake is geweest van eenige Maria-vereering". ${ }^{11}$ ) Waarteen Luther gewaarsku het, is juis dat Maria in die kerk " $n$,helfende Abgöttin" geword het. ${ }^{42}$ )

Tien jaar nadat Luther sy stellings op die kerkdeur te Wittenberg geplaas het (1517), hou hy 'n preek: „Am Tage der Empfängnis der Mutter Gottes", waarin hy die leer van die onbevlekte ontvangenis nog erken, waarin hy sê dat by Maria „,die Eingiessung der Seele ohne Erbsünde sei zugegangen”, dat sy „den ersten Augenblick da sie anfing zu leben ohne alle Sunde (war) ${ }^{\circ .}{ }^{43}$ ) In die latere uitgawe van hierdie preek (nog tydens Luther se lewe) is bogenoemde gedagtes egter geskrap. In sy vertaling en verklaring van die Magnificat (so vroeg as 1521), is die onbevlekte ontvangenis nog geleer. In sy Huispostille leer hy presies die teenoorgestelde: „Die Mutter Maria ist wohl von sündlichen Eltern und in Sünden geboren wie wir."44)

38) Vgl. „Die Bekenntnisschriften der evangèlisch-lutherisch Kirche”, 1930, 2e Auflage, 1952.

39) H. Kemna, "De Hervorming en de Mariavereering", Art. in „Studia Catholica", 14de Jrg. 1938, bls. 312-325.

40) H. Kemna: A.W. bls. 315. Dat Kemna Luther se beskouinge oor Maria in verband bring met sy stryd teen die hele kerk, sy „wrok en verbittering" om sy ,eie posisie te regverdig en die kerk soveel moontlik afbreuk te doen" is heeltemal te negatief gestel. Op grond van sy Sola Scriptura-leer het Luther besef dat verlossing enkel en alleen christologies en nie mariologies aanvaarbaar is nie.

11) H. Kemna, A.W. bls. 312-313.

42 Luther, Werke. Erl. Uitg. V.L. 245. vgl. ook Luther, Werke. Jhena. I, 488.

43 Luther, Werke. Erl. Uitg. XV, 2, 58.

44) Luther, Werke: Erl. VI, 2, 433. 
Later stel Luther die saak so: - Dat sy 'n verhewe vrou was, wil ons aanvaar. Sy moet op die juiste wyse geëer word. Sy het alles wat sy ontvang het, sonder enige verdienste gekry. Volgens Maria se eie verklaring is dit verkeerd om haar tot godin te maak. Hoe meer mens haar verdienste vergroot, des te meer breek jy God se genade af. Deur te groot eer te bring aan Maria, word Christus „verklein".45)

As dit daarop aankom om iemand vanweë sy heiligheid te vereer, dan is ons presies net so heilig as Maria en ander heiliges, hoe groot hulle ookal is, indien ons in Christus glo. Dat sy groter genade gehad het, het nie uit haar eie verdienste voortgekom nie. ..Ons kan nou eenmaal nie almal moeder van God wees nie; origens is sy ons gelyk." ${ }^{\prime 6}$ )

Luther behandel die artikel van die maagdelike geboorte in 'n preek te Wittenberg, 25 Desember 1530. Hy sê dat die hoofvereiste nie moet wees om "soveel moontlik ophef te maak" van die maagdelikheid van Maria nie. Mense het dit "te veel" gedoen, want mens moet veeleer daaroor handel „dat Christus gebore is". Dit kom vir ons nie hoofsaaklik daarop aan dat $\mathrm{Hy}$ uit 'n maagd gebore is nie, maar dat Hy gebore is en dat die Seun van hierdie maagd my gelyk geword het, dat Hy wat God is, so naby my gekom het. Hy het nie die engele aangeneem nie, maar die mens, die saad van Abraham. Hierin lê ons heerlikheid en dit moet ons tot vreugde stem (bls. 45). En alhoewel hy op bladsy 45 sê ..Uit die maagd gebore", "dit is sonder sonde" sê hy tog verder: "Die verkondiging van hierdie geboorte wat deur die engele gedoen is, moet ons herhaal. Hy is vir ons gebore, Hy die Heiland. Nou weet ons dat $\mathrm{Hy}$ ons broeder is, ja veel meer, my eiendom soos 'n man die eiendom van sy vrou is." .Daarom moet ons nie in die eerste plek die artikel so lees dat Christus gebore is uit die maagd Maria nie, maar bowe-al die spreuk en die prediking van die engel, want dit is die eerste en beste prediking wat ook die eerste is wat in die Nuwe Testament gebeur het. Hieruit het alle ander verkondiging in die hele Nuwe Testament voortgevloei (bls. 47." $\$$ i)

\section{KONKLUSIES.}

(1) Uit die Klein en Groot Kategismi is dit duidelik dat Art. 3 van die apostolicum in belangrike plek inneem as „articulus de redemptione". Dieselfde geld die Augustana en die Formula Concordiae waarin Luther se invloed groot is.

45) Luther, Werke: Erl. Uitg. VL, 244 en Jhena: I, 486

46) Luther, Werke: Erl. XV, 2, 495 v.v.

4i) Dr. Martinus Luther: Veertig Leerredenen, uit het Hoogdeutsch Vertaald door P. F. Lodewijks, volgens die uitgawe van E. L. Enders: Dr. Martin Luthers vermischte Predigten (5 Dln.) Frankfurt A/M. 1877-1881, bls. 42-50. 
(2) Alhoewel Luther baie sterk gewaarsku het om Maria nooit tot "helfende Abgöttin" te verhef nie, moet ons sê dat die „Roomskatolieke reste" nie geheel en al verdwyn het nie. So bv. in die preek wat hy so laat as 1530 gehou het te Wittenberg, grond hy o.a. die sondeloosheid van Jesus Christus ook op die maagdelike geboorte.

(3) Luther het duidelik ingesien dat die Rooms-Katolieke Mariologie, Christus "verklein". Op grond van die Skrif het hy daarteen gewaarsku.

(4) Luther het geen waardering vir die Rooms-Katolieke selibaat en virginiteitsstrewe nie, maar ag die huwelik (onder die gesigspunt van die kinderverwekking) as die feitlik enigste Godwelbehaaglike lewensstaat, in teenstelling met Calvyn wat wel skriftuurlike waardering het vir die virginiteit. 